\title{
LATENT HEAT STORAGE SYSTEMS
}

\author{
Dušan Medved', Milan Kvakovský, Vieroslava Sklenárová
}

\begin{abstract}
This paper deals with a latent heat storage system using Phase Change Materials (PCM) as an effective way of storing thermal energy (solar energy, off-peak electricity, industrial waste heat). It has the advantages of high storage density and the isothermal nature of the storage process. This article will show to find a suitable PCM for various purposes a suitable heat exchanger with ways to enhance the heat transfer, and it will show a variety of designs to store the heat using PCMs for different applications, i.e. space heating and cooling, solar cooking, greenhouses, solar water heating and waste heat recovery systems.
\end{abstract}

\section{INTRODUCTION}

Researchers search the new and renewable energy sources to reduce the $\mathrm{CO}_{2}$ emissions from the combustion of fossil fuels, particularly in areas where low temperature applications are involved. Solar energy has an enormous potential for the heating and cooling of buildings, producing hot water for domestic and industrial purposes, cooking, warming greenhouses for agricultural crops, etc. However, solar energy is intermittent, unpredictable, and available only during the day. Hence, its application requires efficient thermal energy storage so that the surplus heat collected during sunshine hours may be stored for later use during the night. Similar problems rise in heat recovery systems, where the waste heat availability and utilization periods are different, requiring some thermal energy storage. In thermal energy storage, the useful energy from the collector is transferred to the storage medium where it is transformed into an internal energy. This may occur in the form of latent heat, sensible heat, or both. Latent heat storage is more attractive than sensible heat storage because of its high storage density with smaller temperature swing. However, many practical problems are encountered with latent heat storage due to low thermal conductivity, variation in thermo-physical properties under extended cycles, phase segregation, subcooling, irregular melting, volume change and high cost. These problems have to be technically resolved before latent heat storage can be widely used. Latent heat storage is a relatively new area of research [1].

\section{LATENT HEAT STORAGE MATERIALS}

Phase Change Materials (PCM) are latent heat storage materials. As the source temperature rises, the chemical bonds within the PCM break up as the material changes phase from solid to liquid (as is the case for solid-liquid PCMs). The phase change is a heat-seeking (endothermic) process and therefore, the PCM absorbs heat. Upon storing heat in the storage material, the material begins to melt when the phase change temperature is reached. The temperature then stays constant until the melting process is finished. The heat stored during the phase change process (melting process) of the material is called latent heat. Latent heat storage has two main advantages: a) it is possible to store large amounts of heat with only small temperature changes and therefore to have a high storage density; b) because the change of phase at a constant temperature takes some time to complete, it becomes possible to smooth temperature variations. The comparison between latent and sensible heat storage shows that using latent heat storage, storage densities typically 5 to 10 times higher can be reached. PCM storage volume is two times smaller than that of water. Latent heat storage can be used in a wide temperature range. A large number of PCMs are known to melt with a heat of fusion in any required 
range. The PCM to be used in the design of thermal storage systems should accomplish desirable thermophysical, kinetics and chemical properties [1].

\subsection{Thermo-physical Properties}

a) Melting temperature in the desired operating temperature range.

b) High latent heat of fusion per unit volume so that the required volume of the container to store a given amount of energy is less.

c) High specific heat to provide for additional significant sensible heat storage.

d) High thermal conductivity of both solid and liquid phases to assist the charging and discharging of energy of the storage systems.

e) Small volume changes on phase transformation and small vapor pressure at operating temperatures to reduce the containment problem.

f) Congruent melting of the PCM for a constant storage capacity of the material with each freezing/melting cycle.

\section{2. $\quad$ Kinetic Properties}

a) High nucleation rate to avoid super cooling of the liquid phase.

b) High rate of crystal growth, so that the system can meet demands of heat recovery from the storage system.

\subsection{Chemical Properties}

a) Chemical stability.

b) Complete reversible freeze / melt cycle.

c) No degradation after a large number of freeze / melt cycles.

d) Non-corrosiveness to the construction materials.

e) Non-toxic, non-flammable, and non-explosive materials for safety.

\section{CLASSIFICATION OF PCM}

There are a large number of PCMs (organic, inorganic and eutectic), which can be identified as PCMs from the point of view melting temperature and latent heat of fusion. However, except for the melting point in the operating range, a majority of PCMs do not satisfy the criteria required for an adequate storage media. As no single material can have all the required properties for an ideal thermal storage media, one has to use the available materials and try to make up for the poor physical properties by an adequate system design. For example, metallic fins can be used to increase the thermal conductivity of PCMs, super-cooling may be suppressed by introducing a nucleating agent in the storage material, and incongruent melting can be inhibited by the use of a PCM of suitable thickness. For their very different thermal and chemical behavior, the list of each sub-group, which affect the design of latent heat storage systems using PCMs of that sub-group, are mentioned below [1]:

a) Paraffins

b) Non-paraffins

c) Fatty Acids

d) Salt Hydrates

e) Eutectics

f) Cross-linked Polyethylene

g) Polyalcohols

\section{LATENT HEAT STORAGE SYSTEMS}

The intermittent and dynamic nature of solar irradiance and the need to utilize solar energy systems in a continuous and static load make the use of storage systems essential in most of the potential uses of solar energy. The use of PCMs can be found in solar energy storage systems for 
water heating, green houses, space heating and cooling, cooking and waste heat recovery systems. The main utilisation is in the following systems:
a) Solar Water Heater
b) Space Heating
c) Space Cooling
d) Greenhouse Heating
e) Solar cooking
f) Waste Heat Recovery Systems

\section{MODELING}

To understand the parameters that affect the performance and economics of a thermal storage system it is possible to develop a model. The thermal behavior of the tank can be simulated by the Schumann equations, which describe the heat transfer between the fluid and a packed bed [2]:

$$
\begin{aligned}
& (\rho \cdot C)_{\mathrm{f}} \cdot \varepsilon \cdot \frac{\partial \vartheta_{\mathrm{f}}}{\partial t}=-\frac{(m \cdot C)_{\mathrm{f}}}{S} \cdot \frac{\partial \vartheta_{\mathrm{f}}}{\partial y}+h \cdot\left(\vartheta_{\mathrm{b}}-\vartheta_{\mathrm{f}}\right) \\
& (\rho \cdot C)_{\mathrm{b}} \cdot(1-\varepsilon) \cdot \frac{\partial \vartheta_{\mathrm{b}}}{\partial t}=h \cdot\left(\vartheta_{\mathrm{f}}-\vartheta_{\mathrm{b}}\right)
\end{aligned}
$$

where:

$S=$ cross sectional area of bed, $\left[\mathrm{m}^{2}\right]$,

$C=$ specific heat of fluid (f) or bed (b), $\left[\mathrm{J}^{\mathrm{kg}}{ }^{-1} \cdot \mathrm{K}^{-1}\right]$

$D=$ particle diameter, $[\mathrm{m}]$,

$h=$ heat transfer coefficient between bed and fluid, [W. $\left.\mathrm{m}^{-2} \cdot \mathrm{K}^{-1}\right]$,

$h_{V}=6 \cdot h \cdot(1-\varepsilon) \cdot \alpha / D=$ volumetric heat transfer coefficient, $\left[\mathrm{W} \cdot \mathrm{m}^{-3} \cdot \mathrm{K}^{-1}\right]$,

$\vartheta=$ temperature of fluid (f) or bed (b), $\left[{ }^{\circ} \mathrm{C}\right]$,

$y=$ vertical dimension, $[\mathrm{m}]$,

$\alpha=$ surface area shape factor,

$\varepsilon=$ void fraction of bed,

$\rho=$ density of fluid (f) or bed (b), $\left[\mathrm{kg} \cdot \mathrm{m}^{-3}\right]$,

$t=$ time, $[\mathrm{s}]$,

and where $f$ subscripted variables denotes fluid properties and $b$ denotes bed properties. The model consisted of a one dimensional, finite difference representation of the above equations. The tank can be divided into equal horizontal slices, typically $0,2 \mathrm{~m}$ thick. The model then can calculate the local heat transfer coefficients, and then calculate the local temperatures of the fluid and the bed using the partial differential equations. There can be used the modified Euler's method to correct the predicted fluid and bed temperatures. The model can repeat the above process at fixed time intervals, typically every few seconds.

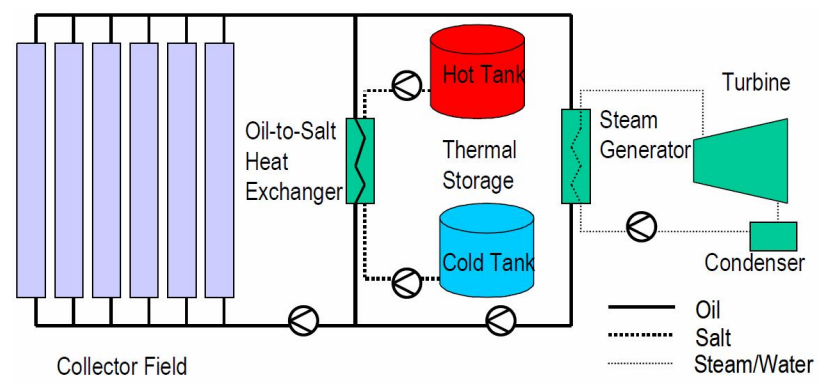

Figure 1 Schematic of a two-tank thermal storage system integrated into a trough plant [2]

Large tanks of water are heated with excess steam generated by solar heaters during peak daylight hours. When power grid requires a sudden surge of power, steam can be bleed of super heated water in these storage tanks. Water is used both as the working medium and heat storage medium resulting in 
short reaction times in response to turbine demand. The greater the drop in turbine steam pressure, the faster the superheated water will boil. These systems are referred to as buffer system. Superheated water is unstable and boils over rapidly when pressure is reduced. It can also be extremely dangerous in the event of tank rupture. In case of rupture water at $200{ }^{\circ} \mathrm{C}$ will transform into water at $100{ }^{\circ} \mathrm{C}$ and a large volume of steam at one atmosphere of pressure (Fig. 2). This transformation is so rapid that boiler explosions have frequently resulted in the destruction of large buildings [3].

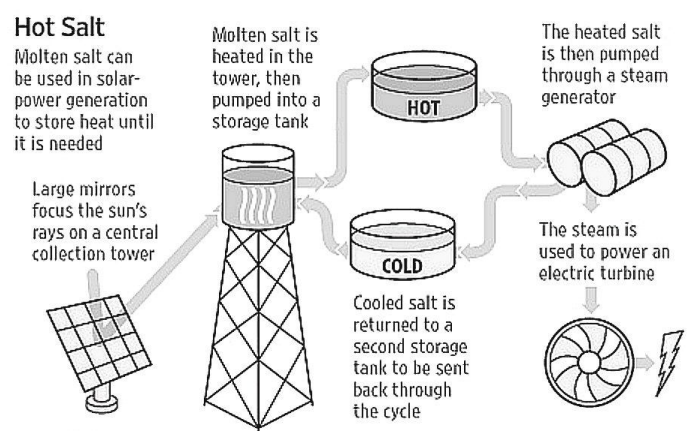

Figure 2 Schematic of a two-tank thermal storage system integrated into a trough plant [4]

\section{CONCLUSION}

This article could help to find the suitable PCM for various purposes, different techniques for the measurement of thermo physical properties of PCM, suitable heat exchanger with ways to enhance the heat transfer and provide the various designs to store the heat using PCM for different applications i.e. space heating / cooling, solar cooking, greenhouse heating, water heating and waste heat recovery systems.

\section{REFERENCES}

[1] Sharma, S. D., Sagara, K.: Latent Heat Storage Materials and Systems. International Journal of Green Energy, 2: 1-56, 2005. Taylor \& Francis Inc. ISSN: 0197-1522.

[2] Pacheco, J. E., Showalter, S. K., Kolb, W. J.: Development of a Molten-salt Thermocline Thermal Storage System for Parabolic Trough Plants. [online], [cited: May 2010], Available on internet < http://www.p2pays.org/ref/22/21032.pdf >

[3] The Energy Matrix: Heat storage. [online], [cited: May 2010], Available on internet $<\mathrm{http}: / /$ www.science-ebooks.com/ematrix1/heat_storage.htm >

[4] Laumer, J.: Molten Salt As Solar Heat Battery. [online], [cited: May 2010], Available on internet $<$ http://www.treehugger.com/files/2008/01/molten_salt_as.php $>$

\section{ACKNOWLEDGEMENT}

This work was supported by project VEGA SR No. 1/0166/10.

\section{Authors:}

Ing. Dušan Medved', PhD.

Technical University of Košice

Faculty of Electrical Engineering and Informatics

Department of Electric Power Engineering

Mäsiarska 74

04201 Košice, Slovak Republic

E-mail: Dusan.Medved@tuke.sk

Tel: +421556023555

Fax: +451556023552
Ing. Milan Kvakovský Ing. Vieroslava Sklenárová

Technical University of Košice Technical University of Košice

Faculty of Electrical Engineering and Informatics Faculty of Electrical Engineering and Informatics

Department of Electric Power Engineering Department of Electric Power Engineering

Mäsiarska 74

04201 Košice, Slovak Republic

Kvakovsky@tuke.sk

Tel: +421556023560

Fax: +451556023552
E-mail: Vieroslava.Cackova@tuke.sk

Tel: +421556023560

Fax: +451556023552 